\title{
O RETRATO FRENTE/VERSO DA APRENDIZAGEM A DISTANCIA NO BRASIL 2009
}

\section{Fredric M. Litto}

CDD: 371.39445

"Foi o melhor dos tempos, foi o pior dos tempos, foi a idade da sabedoria, foi a idade da imbecilidade, foi a época de acreditar, foi a época da descrença, foi a época da Luz, foi a época da Escuridão ..."
"It was the best of times, it was the worst of times, it was the age of wisdom, it was the age of foolishness, it was the epoch of

belief, it was the epoch of incredulity, it was the season of Light, it was the season of Darkness..."

\section{RESUMO}

A aprendizagem a distância no Brasil hoje enfrenta uma época de contrastes conflituosos simultâneos de atos e fatos. No lado positivo, houve, de 2004 a 2008, um crescimento de $1.175 \%$ de universitários estudando a distância, chegando a ter cerca de um milhão de alunos, ou um sexto do total matriculado no ensino superior (o crescimento anual de número de alunos no presencial é de apenas 5\%). Quase 300 instituições estão autorizadas, por diferentes níveis governamentais, para realizar cursos de graduação e pós-graduação (latu senso); e é importante notar o sucesso do fator "extra-territorialidade" (45\% das instituições autorizadas têm até $50 \%$ dos seus alunos residindo em estados que não são o da sede, e $23 \%$ têm mais de $50 \%$ fora do estado sede). Embora seja com atraso que o Brasil entra no rol de países oferecendo ensino superior a distância, é significativo o fato de que instituições de renome já estarem adiantadas no processo (como MIT, Harvard, Oxford, Cambridge e Londres). A potencial contribuição da EAD para o Brasil é incalculável: menos de $40 \%$ dos municípios do país têm uma instituição de ensino superior, e $14 \%$ dos brasileiros têm necessidades especiais que dificultam sua participação no ensino presencial, e que, até agora, têm recebido pouca atenção diferenciada pelas instituições ou pelo governo. $\mathrm{O}$ sucesso dos alunos de EAD no Exame Nacional de Desempenho dos Estudantes (MEC) em 2007, superando os resultados dos alunos presenciais, é uma marca de importância especial. De novo com atraso em relação a muitos outros países, a Universidade Aberta do Brasil já alcançou um corpo discente de 100.000, embora o currículo esteja focalizado apenas na preparação de professores do ensino básico. Mais de 200 universidades corporativas usando EAD demonstram que as empresas no país estão se modernizando na suas capacitações, e a Associação Brasileira de Educação a Distância-ABED continua organizando conclaves nacionais e internacionais, publicando o guia estatístico anual CensoEAD, e em 2009 lançando um novo projeto, pioneiro no mundo, de Certificação de Profissionais de Educação Flexível e a Distância. Do lado que gera preocupações, o obstáculo principal ao desenvolvimento da EAD no Brasil parece ser a mentalidade conservadora demonstrada por docentes universitários (especialmente das faculdades de educação) e sindicatos de professores, que criticam a EAD por "falta de qualidade", sem oferecer exemplos de práticas que não sejam, também, parte do ensino presencial no país, e sem sugerir outras alternativas para aumentar o acesso mais democrático ao conhecimento, que vão além de propostas ingênuas e utópicas. A pesquisa no Brasil sobre EAD revela um desconhecimento da literatura científica internacional (comprovado na falta de citações ao vasto acervo de estudos que existe dentro e fora da web, em teses e artigos em periódicos nacionais), o resultado do fraco domínio de línguas estrangeiras e da quase-inexistência dessa literatura em bibliotecas no país. Essas limitações também diminuem, drasticamente, o uso, por brasileiros, de cursos e recursos educacionais online do exterior na sua aprendizagem. Finalmente, existe um pequeno número de instituições, públicas e privadas, que não se preocupa com a qualidade dos seus programas de EAD, incorrendo em "crimes acadêmicos" como: baixa profundidade e densidade de informação nos seus conteúdos; deficiência na avaliação do desempenho dos seus alunos; um número excessivo de alunos por professor ou tutor, e, consequentemente, um atendimento inadequado aos aprendizes. Outrossim, o ambiente regulatório para a operação de EAD desestimula a criatividade e a diversidade curricular por parte de docentes e instituições, e envolve uma burocracia que prolonga muitos aspectos da oferta de cursos e um processo de avaliação que dá mais ênfase aos "inputs" de programas do que aos "outputs" (o desempenho dos alunos). (FML)

\section{PALAVRAS-CHAVE}

Aprendizagem a distância; Educação a distância; Brasil 


\title{
A SNAPSHOT OF THE FRONT AND BACK OF DISTANCE LEARNING IN BRAZIL IN 2009
}

\begin{abstract}
Distance learning in Brazil today finds itself in a period of simultaneously conflicting contrasts. On the positive side, there was, from 2004 to 2008, a rapid growth $(1,175 \%)$ in the number of post-secondary learners studying by distance education, reaching approximately one million individuals, which represents about one-sixth of the total cohort group (while annual growth in the number of face-to-face students was only about 5\%). Some 300 educational institutions have already been authorized by different levels of government to offer undergraduate and graduate courses through distance learning, and highly significant is the factor of "extra-territoriality" (45\% of authorized institutions have at least $50 \%$ of their student body residing in states other than that of the institution; and $23 \%$ have more than $50 \%$ of the student body in other states). Although Brazil is a late-comer in the large community of countries offering higher education at a distance, it is slowly finding its place within it, encouraged by the presence of distinguished academic institutions such as MIT, Harvard, Oxford, Cambridge, and London. The potential contribution of distance learning to Brazil's growth is enormous: fewer than 40\% of Brazilian counties have any kind of higher education facilities, and $14 \%$ of the Brazilian population have special needs which make difficult participation in face-to-face learning, and which, to date, have received little attention by government or educational institutions. The success, in the Ministry of Education's annual Student Performance Exam, of graduates who studied at a distance has, in a majority of subject areas, exceeded the results of learners who studied through conventional means. Again as a late-comer in relation to other countries, Brazil's Open University, begun in 2007, already has reached enrollments of over 100,000 students, although its curriculum is focused only on the preparation of teachers for primary and secondary education. More than 200 "corporate universities" in the country are already using distance learning to modernize their continuing education programs. The Brazilian Association of Distance Learning (ABED) continues to organize national and international events for academic and corporate educators, publishes an annual statistical survey of distance learning in Brazil (CensoEAD), and in 2009 inaugurated a new project, the first in the world, of Certification of Professionals in Flexible and Distance Learning. On the side which generates concerns, the principal obstacle to the full development of distance learning in Brazil seems to be the conservative mentality demonstrated by university faculty members (especially in schools of education) and teachers' unions, which criticize distance learning for purported "lack of quality," without offering examples of practices which cannot also be found in face-to-face learning in the country, and without suggesting "better" alternatives for augmenting more democratic access to higher learning, and which go beyond proposals ingenuous or utopian. Brazilian research in distance learning reveals lack of knowledge of the international scientific literature, and manifested in the lack, in theses and journal articles, of citations to the vast storehouse of studies both on the web and in hardcopy, the result of the weak dominance of foreign languages and of the essential non-existence of this literature in libraries in the country. These same limitations, of course, drastically reduce the use, by Brazilians, of courses and educational resources online from abroad in their learning. Finally, there exists a small number of institutions, public and private, which make little effort at assuring quality in their distance learning offerings, committing "academic crimes" such as: superficial coverage of course content; inadequate evaluation of course participant performance; excessive number of students per instructor or tutor, and, consequently, insufficient support to learners. Furthermore, the regulatory environment for the operation of distance learning discourages creativity and curricular diversity on the part of instructors and institutions, and involves a bureaucracy which prolongs many aspects of the planning of courses, and an assessment process which gives more emphasis to the "inputs" of programs than to the "outputs" (student performance). (FML)
\end{abstract}

\section{KEYWORDS}

Distance learning; Distance education; Brazil 
Foi com as palavras acima que o celebrado romancista inglês Charles Dickens (1812-1870) abriu seu romance sobre a Revolução Francesa, A História de Duas Cidades (1859). Desde então, muitos autores têm tomado de empréstimo sua ideia de uma época cheia de contrastes conflituosos simultâneos. Acredito que uma "fotografia" do cenário atual da aprendizagem a distância no Brasil revelará esse mesmo conflito de atos e fatos.

\section{O MELHOR DOS TEMPOS}

A Educação no Brasil acompanha a tendência mundial, valendo-se da Educação a Distância (EAD), modalidade que permite ao aluno estudar com flexibilidade de horário e local (via Internet, rádio, televisão, DVDs ou material impresso), e continuar os seus estudos ao longo de toda a vida. O crescimento do setor tem tido uma verdadeira "explosão":

- De 2004 a 2008 houve, no ensino superior nacional, um aumento de número de alunos estudando a distância de 1.175\%; em 2008 havia 760.599 alunos matriculados na graduação (este número representa um sexto do total dos matriculados no ensino superior no país) (WEBER, 2009); o crescimento anual no ensino superior presencial é de, aproxima demente, apenas 5\%;

- Em 2008, quase 400 instituições constavam como credenciadas pelo Ministério da Educação (MEC) e por Conselhos Estaduais da Educação para ministrar cursos de graduação e pós-graduação latu senso (AbraEAD, 2008);

- Um bom indicador da "absorção" da EAD pela população brasileira é o fator de "extraterritorialidade" dos cursos superiores a distância, isto é, de matrículas de alunos de unidades da federação diferentes daquelas da sede das instituições ofertantes dos mesmos cursos: $31 \%$ das instituições têm alunos apenas do mesmo Estado, $45 \%$ das instituições têm até $50 \%$ dos seus alunos em outros Estados, e $23 \%$ têm mais de $50 \%$ dos seus alunos em outros Estados (AbraEAD, 2008, p. 72).

O Brasil agora está tomando seu devido lugar entre os países que fazem amplo uso de EAD para dar acesso ao conhecimento, e à certificação de competências, a camadas cada vez maiores da população. Em diversos países muitas das importantes instituições do ensino superior (como MIT, Harvard, Califórnia, Oxford, Cambridge e Londres) já oferecem 
cursos inteiros de graduação ou pós-graduação online, além de outros recursos educacionais dados gratuitamente via web. Não podemos esquecer que essa modalidade educacional está longe de ser algo nova. Em 2008 a Universidade de Londres comemorou 150 anos de oferta da primeira geração de aprendizagem a distância (cursos por correspondência), tendo outorgado títulos de bacharelado a pessoas que mais tarde se destacaram na política e na ciência, como Mahatma Gandhi, Nelson Mandela, além de cinco cientistas e vários literatos, entre muitos outros, que posteriormente receberam o Prêmio Nobel.

A EAD é a mais lógica solução para atender à demanda reprimida de educação superior, chegando até os alunos nas regiões mais remotas do país (apenas $40 \%$ dos municípios brasileiros têm universidades, faculdades ou centros universitários com cursos presenciais), aos brasileiros que moram em qualquer parte do mundo (a diáspora brasileira), além dos 14\% da população com necessidades especiais (RESENDE, 2009). O aluno que se desloca até um centro metropolitano para estudar presencialmente dificilmente volta para sua região de origem, e acaba iniciando uma vida profissional na metrópole; mas o aluno que fica na sua região, utilizando a EAD para adquirir conhecimento e certificação, aplica seus novos conhecimentos na própria região, para a qual traz progresso.

Não foi surpresa, para quem conhece a EAD, que, em 2007, os universitários que estudaram a distância obtiveram resultados superiores aos daqueles que estudaram presencialmente em sete das treze áreas de conhecimento testadas pelo ENADE-Exame Nacional de Desempenho dos Estudantes (MEC). Quem estuda a distância desenvolve autoestima, senso de responsabilidade e de pro-atividade, e capacidade de aprender com autonomia e com autodisciplina, qualidades apropriadas para um profissional no mercado atual.

A UAB-Universidade Aberta do Brasil, projeto da CAPES-MEC que usa aprendizagem a distância para atender à demanda pelo ensino superior em todos os Estados do país, já tem 100.000 alunos, e coloca o Brasil ao lado de grandes países com instituições similares, como Reino Unido, Alemanha, Canadá, Índia, Paquistão e China. Embora focalizada exclusivamente na preparação de professores para o ensino básico, uma prioridade nacional, a UAB deve crescer, nas próximas décadas, até ser a maior instituição pública do ensino superior no país, ajudando a formar os profissionais qualificados exigidos pela sociedade contemporânea. 
EAD é bastante utilizada, também, pelo universo empresarial e governamental--já existem no Brasil mais de 200 "universidades corporativas" fazendo uso da EAD. A exigência, na altamente competitiva "era de conhecimento", de aprender ao longo da vida, obriga todo profissional a fazer uso de cursos e de auto-didatismo (heutagogia). As redes eletrônicas oferecem ricas oportunidades para essa atualização constante; e entidades especializadas fornecem a certificação de competência quando isso é apropriado. EAD no Brasil também atende à necessidade de educação continuada de executivos, médicos, engenheiros, advogados e profissionais de todas as áreas de conhecimento em virtude da obrigação que têm de se manterem atualizados, somando mais de um milhão e meio de indivíduos nesse setor no país. Vinte e cinco por cento do investimento em educação corporativa no Brasil concentra-se em atividades de EAD, sendo as mais comuns as áreas de Tecnologia, Finanças, Vendas e Gestão de Negócios.

A EAD vai muito além de aprendizagem através de atividades estruturadas em formato de cursos. Quase todas as abordagens atualmente em uso para permitir a aprendizagem via Internet podem ser distribuídas entre três categorias:

- Aquelas que têm estrutura de um curso (seja de 20 minutos, 20 horas ou 20 semanas);

- Aquelas que não têm estrutura de um curso, mas que permitem vários tipos de aprendizagem, como a operação, via Internet2, de equipamentos científicos localizados em centros de pesquisa distantes; a "imersão", via Internet2, em ambientes de realidade virtual; a participação em "comunidades virtuais" de aprendizagem e de prática; e tutoria avulsa;

- Aquelas que disponibilizam acervos em forma digital, como portais coletivos de periódicos científicos; bibliotecas, museus e arquivos virtuais; e repositórios de objetos de aprendizagem, também conhecidos como "conteúdos modulares" (estes, quando de dimensões grandes, normalmente exigem uma ferramenta de diálogo na interface com o aprendiz para determinar o escopo e as características da informação desejada antes de indicar sugestões). 
O site da Associação Brasileira de Educação a Distância-ABED (www2.abed.org.br) oferece um catálogo atualizado de 2.500 cursos a distância de todos os tipos no Brasil, além de manuais e guias de boas práticas de operações de EAD. Sociedade científica sem fins lucrativos, com mais de 2.700 associados, a ABED vem trabalhando desde 1995 para o desenvolvimento de educação a distância aberta e flexível de qualidade. Anualmente, publica o CENSO-EAD.Br, um levantamento estatístico de atividades de EAD em todo o território nacional, tanto do ensino básico e universitário (público e privado) como do mundo empresarial e governamental (CENSO-EAD, 2009).

Além de realizar conclaves nacionais e internacionais para o intercâmbio de novas pesquisas e experiências em EAD, a ABED lançou, em 2009, um projeto pioneiro no mundo - a Certificação Profissional em EAD, uma qualificação não-acadêmica, mas, sim, profissional, baseada na demonstração, através de exame, de competência em alto grau, avaliada por comitês de especialistas. Considerando o grande crescimento da EAD no Brasil, nos últimos anos, é evidente que muitos dos profissionais atualmente trabalhando na área são "improvisados", isto é, formados nas mais diversas áreas acadêmicas e profissionais, frequentemente são, também, indivíduos de grande capacidade, mas sem uma consolidada base teórica e prática na EAD. Somando à experiência prática que possuem o processo de se preparar para o exame a ser ministrado pela ABED, essas pessoas podem aperfeiçoar os seus conhecimentos e, assim, enriquecer sua capacitação para uma atuação profissional na área escolhida. A Certificação Profissional da EAD pela ABED tem validade nacional e, por meio de convênio com a organização EDEXCEL, entidade centenária inglesa, maior certificadora mundial de competências profissionais, o mesmo Certificado tem validade internacional.

\section{O PIOR DOS TEMPOS}

Apesar dos sucessos da EAD em todos os setores de aprendizagem no Brasil, especialmente no tocante à democratização do acesso ao conhecimento avançado, essa abordagem enfrenta uma série de obstáculos, de várias ordens de grandeza, quanto ao conservadorismo mental e à ignorância.

Talvez o obstáculo mais grotesco e lamentável seja o que provém da própria comunidade educacional, que, ao mesmo tempo em que reivindica a expansão cada vez maior 
de acesso ao conhecimento para todas as camadas da sociedade, condena a EAD como se houvesse falta de qualidade, sem justificar essa generalização, contrariando uma vasta literatura científica que demonstra exatamente o contrário. Encontramos a resistência contra a EAD em associações nacionais de pós-graduação e pesquisa em educação, associações de docentes em algumas conceituadas instituições públicas, sindicatos de funcionários universitários e grêmios estudantis, onde essa bandeira às vezes representa, na verdade, um ataque a um governo que está tentando implantar a EAD com objetivos democráticos. A oposição "usa" sua crítica com motivos puramente partidários. Também aparecem com regularidade casos de Assembléias Legislativas, Conselhos Municipais e Estaduais da Educação, Universidades Públicas e Conselhos Regionais de Profissionais injustamente criando decretos, leis e editais que discriminam contra possuidores de diplomas obtidos através de EAD, desobedecendo a equivalência com o presencial garantido pela Lei de Diretrizes e Bases.

De certo, é marcante o silêncio das Faculdades de Educação, onde estão sendo preparados os docentes do futuro, e onde se deveriam estar sendo realizadas investigações sobre a questão de qualidade em educação presencial e a distância. Raramente encontramos disciplinas acadêmicas ou núcleos de pesquisa sobre EAD nessas incubadoras do nosso futuro. É normal encontrarmos, nas Faculdades de Educação, colegiados cujas opiniões representam visões nostálgicas, inflexíveis, e um "campo visual limítrofe" sobre questões de aprendizagem e didática, incluindo a resistência às mudanças em todas as suas formas. Seu discurso é sempre de auto-contradição, de declarações sem a apresentação de evidência corroborativa, talvez sugerindo que os detratores, conscientemente ou não, querem, como prevaleceu em gerações anteriores, manter as camadas brasileiras menos favorecidos sem acesso ao conhecimento. O argumento de eventual "falta de qualidade da EAD" não pode ser usado pelos responsáveis pela situação calamitosa e desastrosa de nossa educação presencial. Quem procura, com seriedade, informações sobre estudos referentes às últimas décadas, que comparam as formas de aprendizagem com e sem o apoio de tecnologia, sabe que é incorreto fazer a pergunta “qual é o melhor?". Thomas Russell (RUSSELL, 2009) acumulou quase 400 estudos sobre o tema e reconheceu que havia boas evidências para ambas abordagens. Outros investigadores (OBLINGER; HAWKINS, 2009; SHEARER, 2009) têm observado que qualquer comparação está repleta de perigos: 
...se nós medirmos os resultados de aprendizagem através de um determinado instrumento de avaliação, e se o curso foi planejado com o mesmo rigor para ambas as plataformas (presencial ou através da tecnologia), então é bem provável que os resultados sejam equivalentes. Na maioria dos casos, isso ocorre por termos planejado o curso para atender aos objetivos de aprendizagem prescritos e intimamente amarrados às questões da avaliação. Essa é a base do que poderíamos chamar de bom desenho instrucional. Mas, como mais de trinta anos de pesquisas já demonstraram, isso não é a pergunta correta. A pergunta não é se ou não podemos obter os mesmos resultados de aprendizagem com a tecnologia, mas como poderíamos usar a tecnologia para enriquecer a experiência educacional, indo além daquilo que pode ser realizado no ambiente presencial ou em qualquer outro ambiente de transferência de conhecimento. (SHEARER, 2009)

Criticar a EAD, sem oferecer evidência concreta de que a modalidade é menos eficaz do que o ineficiente ensino presencial no país, é próprio dos educadores brasileiros que nem sequer sugerem alternativas para aumentar o acesso ao conhecimento, além de suas propostas serem ingênuas e utópicas, tendo em vista as urgências da sociedade nesse setor.

Fazer pesquisa sobre a EAD no Brasil é uma tarefa que encontra obstáculos. Quem tenta usar a Biblioteca Digital Brasileira de Teses e Dissertações do IBICT, ou o Portal de Revistas Científicas da CAPES enfrenta um entrave da maior seriedade: a dificuldade de entender, através do resumo feito pelo autor, de que assunto a obra realmente trata. É evidente que não há nenhuma revisão da qualidade desses resumos, nem nas instituições acadêmicas das quais procedem as pesquisas, nem nas "editorias" dos sites dos bancos de informações. Chegam a ser risíveis as versões em inglês dos resumos das pesquisas brasileiras publicadas nesses sites, provavelmente produzidas por programas de tradução automática; além de frases incompreensíveis, agravam a falta de pela ciência brasileira na comunidade internacional de pesquisa. A ausência, nas bibliotecas universitárias brasileiras, de coleções completas de revistas estrangeiras dedicadas à EAD resulta numa falta quase completa, por autores em nosso país, de referências sobre o uso da literatura científica de todos os continentes. Fica confirmado, assim, o relativo isolamento do país na comunidade internacional da EAD, causado não pela falta de qualidade da nossa produtividade em EAD em si, mas pela ineficaz proficiência em línguas estrangeiras como segunda língua, instrumento de trabalho necessário para qualquer profissional avançado na carreira. $\mathrm{O}$ precário ensino de línguas estrangeiras no Brasil elimina, também, a possibilidade da maior parte da nossa população realizar cursos a distância, ou consultar fontes de informação oferecidas no exterior pelas melhores instituições. Os custos de tradução são altos, e o processo de tradução automática não é confiável; assim, ficamos restritos ao nosso confinado 
alcance lingüístico. Dessa forma, duas questões se impõem: sem oportuna resposta: o Brasil é um país que inova em EAD, ou é um país que meramente segue as inovações de outros países?

Um outro obstáculo ao desenvolvimento de EAD no Brasil são as práticas realizadas por instituições que, de tão empenhadas na busca do Santo Graal (o crescimento cada vez maior de número de alunos ou de retorno no investimento, ou ambos), se esquecem da questão da qualidade de seu produto, ou de seus serviços. Embora sejam uma minoria no contingente de instituições, acadêmicas e corporativas, atuando no país, suas falhas não apenas enfraquecem o ensino que oferecem, mas injustamente expõem a EAD como um todo à crítica de vários setores da sociedade. É possível identificar algumas das características de flagrante baixa qualidade de cursos a distância, e a lista que segue é uma fusão de reclamações de alunos brasileiros de EAD recebidas nos últimos anos pela ABED (Associação Brasileira de Educação a Distância), pela ABE-EAD (Associação Brasileira de Estudantes de Educação a Distância), e pela SEED-MEC (Secretaria de Educação a Distância do Ministério da Educação):

- Abreviação inaceitável do conteúdo coberto pelo curso; um curso de graduação ou de pós-graduação a distância deve ter, aproximadamente, a mesma extensão e profundidade (densidade) de tratamento de conteúdo que os congêneres oferecidos presencialmente pela mesma instituição, ou por instituições de referência no país. Isso não quer dizer que não seja possível inovar nos métodos ou materiais didáticos, mas é imprescindível que cada curso represente para cada aluno uma experiência enriquecedora de novos conhecimentos;

- Inadequação do material impresso distribuído aos alunos, variando entre a superficialidade no tratamento da matéria à redução drástica de um típico livro-texto universitário para uma pequena apostila; o argumento de que "os alunos, pelo seu preparo acadêmico anterior, não aguentam conteúdo otimizado" é inaceitável e condenável; 
- Deficiência na avaliação do desempenho dos alunos, variando de exames apenas no estilo "escolha múltipla" aos exames "multidisciplinares" (nos quais um conjunto das mesmas perguntas é aplicado a alunos de diferentes cursos - economia, pedagogia, ciências sociais;

- Número excessivo de alunos sob a responsabilidade de um único tutor (assistente do professor); embora a tecnologia usada para a realização do curso e a natureza do seu conteúdo possam ser fatores determinantes sobre essa questão, em geral a média de 130:1 é considerada, internacionalmente, como razoável para o atendimento de alunos de EAD, organizados em turmas, em cursos de graduação (e não 500:1 ou mais, como já foi constatado em alguns casos brasileiros);

- Tutores não-qualificados academicamente para atender alunos de determinadas áreas de conhecimento; aqui, o perigo é assumir que apenas indivíduos com diplomas acadêmicos especificamente na área do curso que está sendo ministrado, podem ser considerados "qualificados"; a experiência prática mostra que a competência "legal" (possuir diploma) não é nenhuma garantia de competência "real"; assim, cabe à instituição selecionar como tutores apenas profissionais que podem demonstrar conhecimento real sobre a área de sua especialidade, além de capacidade como mentor. Orientando alunos a distância;

- Insuficiência, em quantidade e qualidade, de apoio material (computadores, livros e periódicos especializados—sejam online ou físicos e equipamentos científicos exigidos pelos cursos) nos centros de atendimento presencial aos alunos; enquanto algumas instituições oferecem cursos a distância, atingindo segmentos da população que dispõem de computadores e redes eletrônicas (ou nas suas residências ou em outros locais, e condições de adquirir um amplo acervo de material bibliográfico sugerido para o acompanhamento do curso), outras instituições se dirigem a segmentos da sociedade nas quais há falta desses recursos-em cada caso, cabe à instituição o planejamento apropriado para o atendimento de seus alunos; 
- Com certeza, é o atendimento ao aluno pela instituição que causa o maior número de reclamações — independentemente da tecnologia adotada para a comunicação (web, emails, ou telefonemas), as respostas a perguntas sobre conteúdo acadêmico, questões de matrícula ou de aspectos financeiros a propósito da relação aluno/instituição, frequentemente levam uma semana ou mais, período excessivo tanto do ponto de vista da aprendizagem como do consumidor; uma boa prática seria que cada instituição anunciasse sua garantia de tempo de resposta às perguntas dos alunos, garantindo essas prestações de serviço.

O ambiente regulatório que trata de EAD no Brasil é outro obstáculo ao crescimento pleno da área. Por um lado, as improbidades de natureza acadêmica e de direitos do consumidor vistos acima demonstram que há numerosos problemas afetando a boa prática de EAD no país. Mas é pouco discutida a melhor forma de garantir a excelência educacional a quem estuda a distância. Por outro lado, encontramos contradição na existência, na Constituição da República Federativa do Brasil (1988), no Artigo 207, quanto ao direito à autonomia, por parte das universidades no que se refere aos assuntos pedagógicos e administrativos. Paralelamente, o Ministério da Educação (MEC) emite portarias e regulamentações sobre a EAD, estabelecendo normas e práticas a serem seguidas para obtenção de "autorização" para oferecer cursos a distância. Se há, na história luso-brasileira, uma forte tradição de supervisão centralizada em órgãos do Estado, então seria aconselhável mudar o Artigo 207, pois configura auto-contradição referir-se a uma "autonomia supervisionada ou monitorada". Em teoria, seria ideal eliminar o Artigo 207 e continuar com a tradição de supervisão e controle; mas as citadas improbidades citadas acima, por parte de algumas instituições, não são poucos, além da morosidade do sistema jurídico nacional, e das brechas da legislação, contribuem para que oportunistas se prevalecem, em interesse próprio, fazendo com que um sistema de auto-regulamentação (como funciona entre as empresas de publicidade no país) ou de um "laissez-faire" seja ainda pior do que o atual. O espaço desse artigo não permite maiores aprofundamentos em torno desse assunto, ou a articulação de argumentos lícitos de ambos os lados; mas, ao menos poderíamos enumerar as dificuldades que a regulamentação atual apresenta para quem faz a EAD no Brasil: 
- A centralização de toda forma de autorização e supervisão da EAD universitária no Brasil cria um gargalo provocado pelo aumento de complexidade nesse setor —quanto mais instituições e alunos participam do processo, mais difícil torna-se o controle (mesmo compudatorizado) de toda a mobilização, por exemplo, para aprovar o pedido de uma universidade para iniciar atividades de EAD, às vezes um prazo suficiente para ocorrer desatualização do programa, da bibliografia e da docência disponível para o curso (VIANNEY, 2008; VIANNEY; TORRES, 2009; LITTO, 2009).

- As instituições reclamam de "não-transparência" por parte do MEC porque não conseguem, como é direito do cidadão na sociedade civil, acompanhar os processos pendentes, as agendas de visitas de avaliadores e a ordem de solicitações para autorizações, entre outras demandas;

- As instituições do setor privado reclamam do "favoritismo" do MEC com relação às entidades federais do ensino superior, cujas autorizações para operar com EAD são velozes e cujas operações têm suas aprovações plenas, quase como um algo automático;

- Muitas instituições, públicas e privadas, reclamam que os averiguadores que realizam a inspeção dos cursos de EAD usam questionários restritos apenas a uma visão ou modelo de operação da EAD, especialmente no tocante à obrigatoriedade de semipresencialidade - fazendo supor que o elaborador do questionário não acredita que um curso universitário a distância possa, ou deva ser, totalmente a distância;

- Outras exigências do MEC para a autorização e continuada aprovação de cursos a distância que merecem ser reconsideradas, são: a obrigatoriedade de pólos de atendimento de alunos com dez computadores, por exemplo, mesmo quando se admite que, pelo custo do curso, o aluno tem esses recursos em casa, tornando possível a redução do custo com a eliminação, nesses casos, dos pólos de atendimento (o pólo, com certeza, é importante para ajudar aqueles alunos que precisam de explicações para consolidar sua compreensão, mas quanto mais avançada for a natureza do curso, menos o aluno precisa de tutelagem); a exigência de título de mestre na área do curso para tutores representa uma interferência na autonomia acadêmica de qualquer instituição, além de não oferecer nenhuma garantia da adequação do indivíduo para a tarefa de tutor. 
Evidentemente, esses problemas representam, parcialmente, as "dores do crescimento" que é integração das políticas de avaliação de EAD por parte do MEC; é de se esperar que o futuro traga um processo de autorização e aferição resultante de uma perspectiva mais ecumênica e menos inflexível. Afinal, nos embates atuais, encontramo-nos terrivelmente divididos entre a desencorajante visão de um pólo de atendimento do aluno a distância localizado numa pequena sala, no andar de cima de uma padaria ou salão de beleza, numa cidadezinha no interior do país, e a visão ainda mais desalentadora de não ter sequer essa possibilidade, quando se deseja aprender.

Duas últimas considerações não podem ser deixadas de lado nesse retrato da realidade da aprendizagem flexível e a distância em nosso país. A primeira se refere ao fato de haver pouco esforço para oferecer um "cardápio" rico de atividades educacionais a distância a uma significativa parte da população com necessidades especiais, e com os mesmos direitos dos demais cidadãos de adquirir novas capacitações e a sua certificação. Quartorze por cento de quase duzentos milhões de pessoas representam uma comunidade não apenas grande, mas também certamente ávida para aprender, com a escola ou universidade vindo até sua casa (um bom argumento contra a exigência de presencialidade em cursos a distância). Mas é difícil encontrar exemplos de oferta de cursos ou de outras formas de aprendizagem destinadas a essa comunidade, mesmo entre instituições públicas. Na mesma categoria encontra-se a absoluta falta, no Brasil, de evidência de criação de Recursos Educacionais Abertos (em inglês: Open Educational Resources), ou a disseminação gratuita, na web, de material apropriado para aprendizagem formal ou não-formal: cursos, objetos de aprendizagem, acervos de bibliotecas, arquivos e sites de museus, entre outras fontes (Capetown Declaration, 2009). ${ }^{8}$ Embora signatário da Declaração de Capetown, em 2007, a ABED não tem conseguido incentivar as instituições educacionais brasileiras a se dedicar a essa atividade beneficente em quantidade significativa-até agora, das três entidades que oferecem REAs, uma apresenta no seu site apenas quatro "minicursos" de curta duração, e as outras duas limitam severamente o acesso de "não-associados" a todo o conteúdo dos seus acervos. 
Como é possível concluir, vivemos, na EAD do Brasil, entre o melhor e o pior dos tempos. As mesmas instituições que oferecem contribuições de grande valor, ao mesmo tempo, contribuem para alguns dos obstáculos que dificultam o desenvolvimento da EAD (LITTO, 2003). Talvez seja esse o preço que pagamos para viver e trabalhar numa democracia em desenvolvimento, permitindo que "curmudgeons", contestadores militantes, como o autor desse artigo, sempre contrários ao fluxo geral das opiniões estabelecidas, tenham a liberdade de fazer suas observações, às vezes acertando e às vezes errando.

\section{REFERÊNCIAS}

ASSOCIAÇÃO BRASILEIRA DE EDUCAÇÃO A DISTÂNCIA - ABRAED. Anuário Brasileiro Estatístico de Educação Aberta E A Distância - ABRAED 2008. São Paulo, SP: Instituto Monitor; ABED, 2008, p. 52-63.

Censo - EaD.Br. São Paulo, SP: ABED, 2009.

CAPETOWNDECLARATION. The Cape Town Open Education Declaration. 15 set. 2007. Disponível em: http://www.capetowndeclaration.org/. Acesso em: jun. 2009.

LITTO, F. M. Aprendizagem a Distância: lições a serem tiradas das experiências nacionais e internacionais. In: SEMINÁRIO INTERNACIONAL SOBRE EDUCAÇÃO A DISTÂNCIA, 2009, Rio de Janeiro. Educação a Distância - $2^{\mathbf{0}}$ Ciclo de Seminários Internacionais. Rio de Janeiro, RJ: Senac Nacional, 2009, p.159-66.

Perspectivas da educação a distância no Brasil: três Cenários a Ponderar [19972002]. Revista Brasileira de Aprendizagem Aberta e a Distância/Brazilian Review of Open and Distance Learning, v.2, n.3, nov. 2003. Disponível em: http://www.abed.org.br/revistacientifica/Revista_PDF_Doc/2003_Perspectivas_Educacao_Di stancia_Brasil_Fredric_Litto.pdf. Acesso em: jun. 2009.

OBLINGER, D. G.; HAWKINS, B. The myth about no significant difference. Educause Rewieu, v.41, n.6, Nov./Dec. 2006. Disponível em: http://net.educause.edu/ir/library/pdf/erm0667.pdf. Acesso em: jun. 2009.

RESENDE, F. Educação Especial e a EAD. In: LITTO, F.; FORMIGA, M. (Org.). Educação a Distância o Estado da Arte. São Paulo, SP: Pearson Education do Brasil, 2009. p. 129-40.

RUSSELL, T. No significant difference Phenomenon. Disponível em: www.nosignificantdifference.org. Acesso em: jun. 2009. 
SHEARER, R. No significant difference and distance education. Disponível em: http://www.distance-educator.com/dnews/Article7507.phtml. Acesso em: jun. 2009.

VIANNEY, J. V. A Ameaça de um modelo único para a EAD no Brasil. Colabor@-Revista Digital da CVA-RICESU, n. esp., set. 2008, p. 29-59.

. ; TORRES, P. L. O Cenário Brasileiro da Educação a Distância. In: COMISSÃO DE EDUCAÇÃO E CULTURA DA CÂMARA DOS DEPUTADOS/CONFEDERAÇÃO NACIONAL DO COMÉRCIO DE BENS, SERVIÇOS E TURISMO-SESC-SENAC, 2009, Rio de Janeiro. Educação a Distância - $\mathbf{2}^{\mathbf{0}}$ Ciclo de Seminários Internacionais. Rio de Janeiro, RJ: Senac Nacional, 2009. p.103-43.

WEBER, D. Jornal O Globo, 10 de maio de 2009. 